\title{
Car safety seats for children: rear facing for best protection
}

\author{
B Henary, C P Sherwood, J R Crandall, R W Kent, F E Vaca, K B Arbogast, M J Bull
}

Injury Prevention 2007;13:398-402. doi: 10.1136/ip.2006.015115

See end of article for authors' affiliations

.....................

Correspondence to:

J R Crandall, University of

Virginia, Center for Applied

Biomechanics, 1011 Linden

Avenue, Charlottesville, VA

22902, USA; jrc2h@

virginia.edu

Accepted 28 August 2007

\begin{abstract}
Objective: To compare the injury risk between rear-facing (RFCS) and forward-facing (FFCS) car seats for children less than 2 years of age in the USA.

Methods: Data were extracted from a US National Highway Traffic Safety Administration vehicle crash database for the years 1988-2003. Children 0-23 months of age restrained in an RFCS or FFCS when riding in passenger cars, sport utility vehicles, or light trucks were included in the study. Logistic regression models and restraint effectiveness calculations were used to compare the risk of injury between children restrained in RFCSs and FFCSs.

Results: Children in FFCSs were significantly more likely to be seriously injured than children restrained in RFCSs in all crash types (OR $=1.76,95 \% \mathrm{Cl} 1.40$ to 2.20$)$. When considering frontal crashes alone, children in FFCSs were more likely to be seriously injured $(O R=1.23)$, although this finding was not statistically significant $(95 \% \mathrm{Cl} 0.95$ to 1.59). In side crashes, however, children in FFCSs were much more likely to be injured (OR $=5.53,95 \% \mathrm{Cl} 3.74$ to 8.18$)$. When 1 year olds were analyzed separately, these children were also more likely to be seriously injured when restrained in FFCSs (OR=5.32, 95\% Cl 3.43 to 8.24). Effectiveness estimates for RFCSs (93\%) were found to be 15\% higher than those for FFCSs (78\%).

Conclusions: RFCSs are more effective than FFCSs in protecting restrained children aged 0-23 months. The same findings apply when 1 year olds are analyzed separately. Use of an RFCS, in accordance with restraint recommendations for child size and weight, is an excellent choice for optimum protection up to a child's second birthday.
\end{abstract}

1 $\mathrm{n}$ the USA, the rate of vehicle occupant deaths for children $1-$ 3 years old has decreased by over $50 \%$ in the last 30 years $^{1}$ largely due to increased use of child restraint systems. Despite these impressive declines, however, motor vehicle crashes remain the leading cause of death for children 1-4 years of age. ${ }^{2}$

Although current child restraint systems have been shown to be effective, further reductions in child passenger injuries may be achieved by improving car seat features and designs. In particular, the orientation of car seats (rear facing or forward facing) probably plays a significant role in car seat effectiveness. By supporting the entire posterior torso, neck, head, and pelvis, a rear-facing car seat (RFCS) distributes crash forces over the entire body rather than focusing them only at belt contact points. In contrast with a forward-facing car seat (FFCS), an RFCS supports the child's head, preventing the relatively large head from loading the proportionately smaller neck with relatively weak neck musculature. ${ }^{3}$ The primary question regarding car seat orientation is at what age children should make the transition to an FFCS, given that both biomechanical and practical considerations have to be taken into account.

In the USA, the American Academy of Pediatrics and the National Highway Traffic Safety Administration (NHTSA) have developed guidelines stating that a child should be at least 1 year of age and weigh at least 20 pounds before transitioning from an RFCS to an FFCS. ${ }^{45}$ The age of the child, in particular, is an important factor which correlates with the material properties of the child's anatomy, such as muscular development and ossification of the cervical spine. Although the policy of the American Academy of Pediatrics states "for optimal protection, the child should remain rear facing until reaching the maximum weight for the car safety seat, as long as the top of the head is below the top of the seat back", a common interpretation of these guidelines by parents and caregivers has been that children should be automatically switched to an
FFCS when they are 1 year old or $9.2 \mathrm{~kg}$ (20 pounds). For this reason, few children in the USA remain rear facing past their first year of age, despite the fact that there are currently many RFCSs that have maximum weight limits beyond $9.2 \mathrm{~kg}$. In fact it has been reported that more than $30 \%$ of children are turned forward facing before they reach 1 year of age. ${ }^{6}$

In Sweden, children remain in RFCSs up to the age of 4 and transition directly from the RFCS to a booster seat. Swedish researchers have used data from a Volvo crash study to compare the effectiveness of these restraints, ${ }^{78}$ although the lack of widespread FFCS usage only allows comparison between RFCSs and forward-facing booster seats. Their most recent study found that RFCSs had an effectiveness of $90 \%$, relative to unrestrained children, and the authors supported the policy of children remaining in an RFCS up to the age of 4 years.

The objective of this paper is to quantitatively compare the ability of RFCSs and FFCSs to protect child occupants aged 0-23 months, with a particular focus on those 12-23 months of age, when involved in motor vehicle crashes, using US data.

\section{METHODS}

The National Automotive Sampling System Crashworthiness Data System (NASS-CDS) is a nationwide motor-vehicle crash data collection program operated by the NHTSA. This ongoing survey provides a representative database of fatal and non-fatal motor vehicle crashes in the USA. The NASS-CDS design, sampling, and weighting process permits crash estimates to be extrapolated to provide national estimates. ${ }^{9}$

As few children in the USA use an RFCS past their second birthday, child passengers under the age of 2 years were selected from the NASS-CDS for calendar years 1988-2003. For

Abbreviations: FFCS, forward-facing car seat; ISS, Injury Severity Score; NASS-CDS, National Automotive Sampling System Crashworthiness Data System; NHTSA, National Highway Traffic Safety Administration; RFCS, rear-facing car seat 
the remainder of this paper, children before their first birthday (0-11 months) will be referred to as "infants" and children between 1 year of age and their second birthday (1223 months) will be referred to as " 1 year olds". Children riding in front or rear seats of passenger cars, sport utility vehicles, light trucks, and vans were included in the study. Children exposed to deployed airbags, vehicle fires, or involved in rollover crashes were excluded. Car seat orientation, seating position, crash direction, crash severity, injury severity, and mortality outcome were extracted from the database. As the database contains limited information on the misuse of car seats, cases were only excluded when the car seat orientation was not in accordance with the manufacturer's specified orientation. To generate risk estimates at the national level, the CDS sampling weight variable ratio inflation factor ("RATWGT") was applied to the unweighted data.

Vehicles were classified according to their body type as passenger cars or light truck vehicles (sport utility vehicles, light trucks, and vans). Vehicle mass was used as a surrogate for vehicle size within these two classifications. The change in velocity during a crash, $\Delta \mathrm{V}$, was used as a proxy for crash severity. The principal direction of force was used to determine crash direction and was categorized as frontal ( 11 to 1 o'clock), right side ( 2 to $4 \mathrm{o}^{\prime}$ clock), left side ( 8 to $10 \mathrm{o}^{\prime}$ clock), and rear ( 5 to 7 o'clock).

As vehicle interior intrusion may play a role in the severity of occupant injuries, an additional variable was generated to capture the child seating position relative to the direction of the crash and its proximity to the location of the car seat. This variable, called "proximity", was used as a covariate in the logistic regression models. The variable was coded " 1 " if the child was sitting in a position closest to the plane of intrusion, and " 0 " if the child was seated in any other position.

The data were analyzed in several steps. Firstly, a descriptive analysis was performed to describe the characteristics of the sample population, using both unweighted and weighted data. Group mean differences for continuous variables were tested against the $t$ distribution, and differences between group proportions were tested against the $\chi^{2}$ distribution.

Next, a multiple logistic regression analysis was performed using the weighted data with the Injury Severity Score (ISS) $\geqslant 9$ as the outcome measure. ${ }^{10}$ An ISS value of 9 or greater is considered to represent moderate and severe injuries. ${ }^{11}$ Results of these analyses are presented as adjusted odds ratios (ORs), and $95 \%$ CIs of the risk estimates were generated from the adjusted models. $\mathrm{p} \leqslant 0.05$ was considered significant.

Thirdly, car seat effectiveness $(\epsilon)$ was calculated using the probabilities from the multiple logistic regression models. Effectiveness $(\epsilon=100 \times((\mathrm{IU}-\mathrm{I}) / \mathrm{IU})$, where $\mathrm{IU}=$ rate of severely injured unrestrained children, and $\mathrm{I}=$ rate of severely injured children in car seat) within a population of child occupants is an estimate of the percentage reduction in the rate of an injury of specified severity if all children changed from being unrestrained to being users of the car seat type of interest. ${ }^{12}$ Thus, the effectiveness of each type of car seat was

Table 1 Car safety seat orientation by child age (unweighted data)

\begin{tabular}{lrll}
\hline Age & \multicolumn{1}{l}{ RFCS } & FFCS & Total \\
\hline Infants & $292(70.2)$ & $124(29.8)$ & $416(100.0)$ \\
1 year olds & $60(13.2)$ & $394(86.8)$ & $454(100.0)$ \\
Total & $352(40.5)$ & $518(59.5)$ & $870(100.0)$ \\
\hline
\end{tabular}

FFCS, front-facing car seat; RFCS, rear-facing car seat. Values are number (\%). Infants were aged 0-11 months, and 1 year olds were aged 12-23 months. calculated relative to the reference group defined as unrestrained children.

Logistic regression models were adjusted for several confounders to calculate the logit estimates that were eventually used to calculate the ORs and their significance. These confounders included child age, vehicle body type, vehicle weight, $\Delta \mathrm{V}$, seating position, seating location, proximity, and the direction of the crash (unless direction was specified in the model, eg, frontal, side, etc). A variable was considered to be a confounder if it significantly changed the coefficient of the principal covariate after being added to the model, and if it improved the fitness of the model.

The multiple logistic regression models were developed for children in frontal, side, and all crashes. In all models, the OR represents the relative risk of ISS 9+ injury in those children restrained in an FFCS compared with those restrained in an RFCS. The logit estimates and the probabilities (adjusted to potential confounders) were used to calculate the effectiveness of the restraint systems relative to the unrestrained children.

When the probability (or effectiveness) as a function of car seat type was calculated, it was necessary to assign a value to each of the rest of the independent variables. Vehicle weight was assigned its median value $(1240 \mathrm{~kg})$, and the value of $\Delta \mathrm{V}$ was prescribed as $48 \mathrm{~km} / \mathrm{h}$. The vehicle type was set to passenger cars, the seating position was set to second seat row, and the child location was set to middle seat. The probability and effectiveness estimates were calculated as functions of restraint type and child age for all crash directions combined (the variable crash direction was not included in the adjusted effectiveness models).

\section{RESULTS}

A total of 1840 children met the age and crash criteria. After removal of children who were unrestrained $(21 \%)$ or had significant restraint misuse $(8 \%)$ and cases with unknown restraint use/type (23\%), 870 children under the age of 2 were used in the study (352 RFCS, 518 FFCS). After application of the NASS weighting factors to reflect national estimates, the cases represented 191068 children in RFCSs and 272153 children in FFCSs. Table 1 shows the distribution of car seat orientation by child age. As expected, the RFCS group were significantly younger than the FFCS group.

Table 2 gives a description of the child, crash, and vehicle characteristics using the weighted data. The weighted data trends were similar to those of the unweighted data, with the primary differences between groups being child age, weight, and height. The significant differences between other variables were primarily due to the large sample size, rather than substantial differences between the groups.

Table 3 gives OR (95\% CI) derived from the adjusted logistic regression models using the weighted data. The models were adjusted for child age, vehicle body type, vehicle weight, $\Delta \mathrm{V}$, seating position, seating location, and direction of crash.

Compared with the RFCS group, the children in the FFCS group were more likely to sustain ISS 9+ injuries in side crashes $(\mathrm{OR}=5.53,95 \% \mathrm{CI} 3.74$ to 8.18$)$, and in all crashes $(\mathrm{OR}=1.76$, $95 \%$ CI 1.40 to 2.20 ). The benefit of rear facing had borderline significance when considering frontal crashes alone $(\mathrm{OR}=1.23$, 95\% CI 0.95 to 1.59 ). When the previous analysis was repeated for infants and 1 year olds separately, the use of an RFCS was beneficial for infants in side crashes and all crashes, and for 1 year olds in frontal crashes and all crashes, with ORs ranging from 1.79 to 6.16. Estimates for other age and crash direction combinations were unable to be calculated because of small sample sizes.

Table 4 shows the effectiveness of each type of car seat in preventing injuries of moderate to great severity, calculated 
Table 2 Child, vehicle, and crash characteristics (weighted data)

\begin{tabular}{|c|c|c|c|c|c|}
\hline & $\begin{array}{l}\text { RFCS } \\
(n=191068)\end{array}$ & $\begin{array}{l}\text { FFCS } \\
(n=272 \quad 153)\end{array}$ & $\begin{array}{l}\text { Total } \\
\text { ( } N=463221)\end{array}$ & $t$ test/ Pearson $\chi^{2}$ & p Value \\
\hline \multicolumn{6}{|l|}{ Age (months) } \\
\hline $0-11$ & $151510(83.0 \%)$ & $63184(23.2 \%)$ & $221694(47.9 \%)$ & \multirow[t]{2}{*}{$\chi^{2}(1)=255650$} & \multirow[t]{2}{*}{$<0.001$} \\
\hline $12-23$ & $32558(17.0 \%)$ & 208969 (76.8\%) & $241527(52.1 \%)$ & & \\
\hline \multicolumn{6}{|l|}{ Sex } \\
\hline Male & $87812(46.0 \%)$ & 125005 (45.9\%) & 212817 (45.9\%) & \multirow[t]{3}{*}{$\chi^{2}(2)=1.49$} & \multirow[t]{3}{*}{0.475} \\
\hline Female & $97831(51.2 \%)$ & 139577 (51.3\%) & $237408(51.3 \%)$ & & \\
\hline Unknown & 5425 (2.8\%) & $7571(2.8 \%)$ & 12996 (2.8\%) & & \\
\hline Weight (kg) & $7.6(2.3)$ & $12.0(3.7)$ & $10.1(3.9)$ & $t=-580$ & $<0.001$ \\
\hline Height $(\mathrm{cm})$ & $62.7(9.9)$ & 72.7 (11.3) & $67.2(16.9)$ & $t=-365$ & $<0.001$ \\
\hline \multicolumn{6}{|l|}{ Vehicle type } \\
\hline Passenger car & 147758 (77.3\%) & 215932 (79.3\%) & $363690(78.5 \%)$ & \multirow[t]{4}{*}{$\chi^{2}(3)=19050$} & \multirow[t]{4}{*}{$<0.001$} \\
\hline SUV & $14559(7.6 \%)$ & $11110(4.1 \%)$ & $25669(5.5 \%)$ & & \\
\hline Van & $12046(6.3 \%)$ & 35072 (12.9\%) & $47118(10.2 \%)$ & & \\
\hline Light truck & $16705(8.7 \%)$ & 10039 (3.7\%) & $26744(5.8 \%)$ & & \\
\hline Vehicle weight $(\mathrm{kg})$ & $1369(304.1)$ & $1328(343.2)$ & $1344(343.3)$ & $t=42.2$ & $<0.001$ \\
\hline \multicolumn{6}{|l|}{ Crash direction } \\
\hline Frontal & 88422 (46.3\%) & $152967(56.2 \%)$ & $241389(52.1 \%)$ & \multirow{5}{*}{$\chi^{2}(3)=6791$} & \multirow[t]{5}{*}{$<0.001$} \\
\hline Rear & $13572(7.1 \%)$ & 29208 (10.7\%) & 42780 (9.2\%) & & \\
\hline Right side & 19009 (10.0\%) & $11701(4.3 \%)$ & $30710(6.6 \%)$ & & \\
\hline Left side & $17118(9.0 \%)$ & $29422(10.8 \%)$ & $46540(10.1 \%)$ & & \\
\hline Unknown & $52947(27.7 \%)$ & 48855 (18.0\%) & $101802(22.0 \%)$ & & \\
\hline \multicolumn{6}{|l|}{ Child row } \\
\hline First & $53513(28.1 \%)$ & 53875 (19.8\%) & $107388(23.2 \%)$ & \multirow[t]{4}{*}{$\chi^{2}(1)=12944$} & \multirow[t]{4}{*}{$<0.001$} \\
\hline Second & 136905 (71.7\%) & $202802(74.6 \%)$ & $339707(73.3 \%)$ & & \\
\hline Third & $639(0.3 \%)$ & $15476(5.7 \%)$ & $16115(3.5 \%)$ & & \\
\hline Unknown & $11(0.0 \%)$ & $0(0.0 \%)$ & $11(0.0 \%)$ & & \\
\hline$\Delta \mathrm{V}(\mathrm{km} / \mathrm{h})$ & $17.0(9.4)$ & $19.8(10.2)$ & $18.7(12.8)$ & $t=-72.8$ & $<0.001$ \\
\hline \multicolumn{6}{|l|}{ MAIS score } \\
\hline 0 & 171706 (89.9\%) & 230695 (84.8\%) & 402401 (86.9\%) & \multirow[t]{8}{*}{$\chi^{2}(7)=3400$} & \multirow[t]{8}{*}{$<0.001$} \\
\hline 1 & $18297(9.6 \%)$ & 38363 (14.1\%) & $56660(12.2 \%)$ & & \\
\hline 2 & $570(0.3 \%)$ & $1220(0.5 \%)$ & $1790(0.4 \%)$ & & \\
\hline 3 & $54(0.03 \%)$ & $625(0.2 \%)$ & $679(0.2 \%)$ & & \\
\hline 4 & $74(0.04 \%)$ & $520(0.19 \%)$ & $594(0.13 \%)$ & & \\
\hline 5 & $312(0.16 \%)$ & $50(0.02 \%)$ & $362(0.08 \%)$ & & \\
\hline 6 & $0(0.0 \%)$ & $42(0.02 \%)$ & $42(0.01 \%)$ & & \\
\hline Unknown & $55(0.03 \%)$ & $638(0.23 \%)$ & $693(0.15 \%)$ & & \\
\hline \multicolumn{6}{|c|}{ MAIS (injured \& uninjured) } \\
\hline Frontal crashes & $0.20(0.5)$ & $0.20(0.4)$ & $0.20(0.5)$ & $t=0.6$ & 0.862 \\
\hline Side crashes & $0.09(0.3)$ & $0.26(0.5)$ & $0.18(0.5)$ & $t=-54.5$ & $<0.001$ \\
\hline All crashes & $0.11(0.4)$ & $0.17(0.4)$ & $0.14(0.4)$ & $t=-43.7$ & $<0.001$ \\
\hline
\end{tabular}

FFCS, front-facing car seat; MAIS, Maximum Abbreviated Injury Score; RFCS, rear-facing car seat; SUV, sports utility vehicle.

Values are number (\%) or mean (SD).

with respect to unrestrained children, based on the adjusted logistic regression models. RFCSs had higher effectiveness values than FFCSs for each age group (infants, 1 year olds, all). The estimates were age sensitive, as they were higher for infants than for 1 year olds.

\section{DISCUSSION}

Regardless of the age group considered, RFCS use resulted in lower risk of injury than FFCS use for crashes of all directions. The unexpected finding from these results is the higher benefit for children in RFCSs compared with FFCSs in side impact crashes. The biomechanical benefits of RFCSs are primarily apparent in frontal impacts. In fact, in a purely lateral crash, the only significant differences between RFCSs and FFCSs are the geometry of the side wings and the location at which the restraint attaches to the vehicle. Most side crashes, however, are not purely lateral and probably have a forward component. ${ }^{13}{ }^{14}$ When a child is in an RFCS, a frontal crash component results in the head moving farther into the car seat "cocoon" with the likelihood of additional protection of the side wings. When in an FFCS, a frontal crash component causes the child's head to move forward and further away from the car seat, limiting or removing any benefit of the side wings. Further research is necessary to determine if this factor is responsible for the significant benefit of RFCSs in side crashes, or if other factors are also important.

It is also notable that RFCSs had higher effectiveness values than FFCSs for each age group considered (infants, 1 year olds,

Table 3 Adjusted odds ratios of Injury Severity Score (ISS) 9+ comparing forward-facing with rear-facing car seats

\begin{tabular}{|c|c|c|c|}
\hline Adjusted models & Frontal crashes & $\begin{array}{l}\text { Side crashes } \\
\text { (right and left) }\end{array}$ & $\begin{array}{l}\text { All crashes } \\
\text { (including rear) }\end{array}$ \\
\hline Without proximity term & $1.23(0.95$ to 1.59$)$ & 3.51 (2.29 to 5.41$)$ & 2.24 (1.77 to 2.84$)$ \\
\hline With proximity term & $1.23(0.95$ to 1.59$)$ & 5.53 (3.74 to 8.18$)$ & 1.76 (1.40 to 2.20 ) \\
\hline Infants only & $\mathrm{N} / \mathrm{A}(\mathrm{N} / \mathrm{A})$ & 2.75 (1.81 to 4.18$)$ & 1.79 (1.18 to 2.72 ) \\
\hline 1 year olds only & $6.16(3.98$ to 9.51$)$ & $\mathrm{N} / \mathrm{A}(\mathrm{N} / \mathrm{A})$ & 5.32 (3.43 to 8.24$)$ \\
\hline
\end{tabular}


Table 4 Effectiveness of rear-facing (RFCS) and frontfacing (FFCS) car seats in preventing injuries of Injury Severity Score 9+

\begin{tabular}{llll}
\hline & \multicolumn{3}{l}{ Car seat effectiveness $(\%)$} \\
\cline { 2 - 4 } Car seat & Infants & $\mathbf{1}$ year olds & All \\
\hline RFCS & 97.2 & 86.2 & 93.2 \\
FFCS & 93.7 & 69.3 & 78.0 \\
\hline
\end{tabular}

Infants were aged 0-11 months, and 1 year olds were aged 12-23 months.

all). For all ages and crash directions, RFCS effectiveness was 93\% compared with $78 \%$ for FFCS effectiveness. Although a slightly different definition of injury was used in this study (ISS $9+)$, this value is comparable to a Swedish estimate of $90 \%$ RFCS effectiveness based on an injury threshold of Maximum Abbreviated Injury Scale $2+{ }^{8}$

One of the weaknesses of this dataset is the fact that the ages of the children are quantified only in terms of years, with no month data. The effect is that children at different developmental stages are grouped together. For example, both 0 and 11-month-old children are grouped as infants, and both 12 and 23-month-old children are grouped as 1 year olds. The rapid change in size and injury tolerance in the first 2 years of life certainly would affect these results. This limitation might be less important if the two car seat groups had a normalized spread of data across all age ranges. However, other populationbased data suggest that both groups are skewed, with few children in the upper age range using RFCSs, and few children in the lower age range using FFCSs (PCPS Kallan, personal communication).

This limitation, however, may cause the primary finding (lower injury risk in RFCSs) to be conservative. The main difference between the actual data and the "ideal" dataset is that the youngest children are under-represented in the FFCS group, and the oldest children are under-represented in the RFCS group. With the assumption that injury tolerance increases with age, ${ }^{15}$ we are under-representing children in the RFCS group who would have lower injury risk. The effect is that the predicted injury risk of the entire RFCS group is overestimated. By the same token, by under-representing the youngest forward-facing children who would probably have lower injury tolerance, the predicted injury risk of the entire FFCS group is underestimated. Although other factors that correlate with age, such as height, can also be expected to have a critical role in the results, it is likely that the age and injury tolerance relationship is one of the most critical.

These findings have significant implications for the child passenger safety community as well as for anticipatory guidance efforts by pediatricians. In the USA, although the American Academy of Pediatrics currently states that children should remain in RFCSs beyond their first birthday, this message is somewhat overshadowed by the more highly publicized 12 months and 20 pounds guideline. Clinicians should consider emphasizing the use of RFCSs beyond age 1 in their consultations with parents. NHTSA and child passenger advocacy groups should also be encouraged to emphasize this recommendation in their policy statements and educational programs. It is expected that these findings will also be applicable to the international community, although the different vehicle environments in other countries must be considered.

These findings also have significant implications for car seat manufacturers. Although RFCS designs have changed in recent years to accommodate older children, few if any restraints are available in the USA of appropriate size for children up to their
Key points

- Children 0-23 months were less likely to be severely injured when using a rear-facing car seat (RFCS) than a front-facing car seat (FFCS).

- The benefit of an RFCS was also evident when only children from 12-23 months were included.

- The benefit of an RFCS was particularly great in side crashes.

2nd birthday. These research findings in concert with higher demand for these restraints should encourage new RFCS designs. At higher weight limits, however, some RFCS designs may not be able to pass current US testing standards. Larger RFCSs are available in Europe, which often incorporate support legs or bases which extend to the vehicle floor to support the restraint. Support legs are currently not allowed in US safety standards, although these regulations should be reviewed if these designs prove to be beneficial.

Finally, these findings cannot be analyzed in a vacuum. The child passenger safety environment is a very complex one which includes a range of considerations: biomechanics, education, misuse, car seat cost, vehicle design, compliance standards, etc. Although we are confident that an immediate delay in the transition from RFCS to FFCS with currently available car seats will decrease the injury risk for child passengers, these results should also be considered as part of an overall evolution of child passenger safety. The goal should be to evolve toward a progression of restraint systems that provide a safety benefit that meets or exceeds that afforded to adults, while simultaneously being simple to understand, install, and use correctly.

\section{IMPLICATIONS FOR PREVENTION}

Results of this study reflect that RFCSs are more effective in protecting restrained children aged 0-23 months and are associated with less likelihood of severe injury than FFCSs. Of importance, these findings apply specifically to 1 year olds in all crashes. To take maximum advantage of car seat protection, parents should prolong use of the RFCS (in accordance with restraint recommendations for child size and weight).

\section{ACKNOWLEDGEMENTS}

This publication was supported by a grant from the US Centers for Disease Control and Prevention (CDC). Its contents are solely the responsibility of the authors and do not necessarily represent the official views of the CDC.

\section{Authors' affiliations \\ B Henary, C P Sherwood, J R Crandall, R W Kent, Center for Applied \\ Biomechanics, University of Virginia, Charlottesville, VA, USA \\ F E Vaca, Center for Trauma and Injury Prevention Research, University of California, Irvine, CA, USA \\ K B Arbogast, Center for Injury Research and Prevention, Children's Hospital of Philadelphia, Philadelphia, PA, USA \\ M J Bull, Department of Pediatrics, Indiana University School of Medicine, Indianapolis, IN, USA}

Competing interests: None.

\section{REFERENCES}

1 Insurance Institute for Highway Safety (IIHS). Insurance Institute for Highway Safety fatality facts. Arlington, VA: Insurance Institute for Highway Safety, 2005 . 
2 Hoyert DL, Heron MP, Murphy SL, et al. Deaths: final data for 2003. National vital statistics reports. Hyattsville, MD: National Center for Health Statistics, 2006;54(13)

3 Weber K. Crash protection for child passengers. A review of best practice. University of Michigan Transportation Research Institute (UMTRI) 2000;31:1-27.

4 American Academy of Pediatrics (AAP). Car safety seats: a guide for families 2007. http://www.aap.org/family/carseatguide.htm (accessed 4 Jun 2007).

5 National Highway Traffic Safety Administration. General child seat use information (2006). http://www.nhtsa.dot.gov (accessed 14 Nov 2006).

6 Partners for Child Passenger Safety. 2000 interim report. http:// www.chop.edu/download/Interim_report.pdf (accessed 11 Oct 2007)

7 Isaksson-Hellman I, Jakobosson L, Gustafsson C, et al. Trends and effects of child restraint systems based on Volvo's Swedish accident database. SAE-973299. In Proceedings of Child Occupant Protection 2nd Symposium, P-316, Society of Automotive Engineers, Inc. Warrendale, PA, 1997.

8 Jakobsson, L, Isaksson-Hellman, I, Lundell, B. Safety for the growing child: experiences from Swedish accident data. Paper No 05-0330. Proceedings of the 19th International Technical Conference on the Enhanced Safety of Vehicles, 2005.
9 National Highway Traffic Safety Administration. National Automotive Sampling System (NASS), Crashworthiness Data System, analytical user manual. Washington, DC: National Center for Statistics and Analysis, National Highway Traffic Safety Administration, US Department of Transportation, 2001.

10 Baker SP, O'Neill B, Haddon W, et al. The injury severity score: a method for describing patients with multiple injuries and evaluating emergency care. J Trauma 1974;14:187-96.

11 Evans L. Traffic safety and the driver. New York: Van Nostrand Reinhold, 1991

12 Beattie, TF, Currie, CE, Williams, JM, et al. Measures of injury severity in childhood: a critical overview. Inj Prev 1998;4:228-31.

13 Sherwood C, Crandall JR, Ferguson S. Factors leading to crash fatalities to children placed in child restraints. Proceedings of the 47th Association for the Advancement of Automotive Medicine Conference, 2003.

14 Arbogast, K, Ghati, Y, Menon, RA, et al. Field investigation of child restraints in side impact crashes. Traffic Inj Prev 2005;6:351-60.

15 Burdi, AR, Huelke, DF, Snyder, RG, et al. Infants and children in the adult world of automobile safety design: pediatric and anatomical considerations for design of child restraints. J Biomech 1969;2:267-80.

\section{LACUNAE}

\section{Israeli transport ministry pledges nationwide road safety plan}

sraeli prime minister Ehud Olmert announced in August that he would restore the 150 million shekels (€27 million, US\$36 million) cut from the budget of the campaign to fight traffic incidents bringing it back up to 550 million shekels (€98 million, US\$133 million).

Although clearly influenced by the recent spate of fatal incidents, sources close to the prime minister insisted that this decision was not a reversal, explaining that the cut had been proposed by officials at the treasury. At the cabinet meeting on 26 August, a report was presented to ministers by ministry of transportation officials and members of the National Road Safety Authority, covering 1997 to 2006.

"The accidents have become more lethal and the situation is troubling," Olmert said. "The minister of transport [Shaul Mofaz] will be given all the tools to carry out a genuine campaign against accidents-both in terms of prevention through education and also by improving the infrastructure".

According to data presented at the meeting, the number of children aged 1 to 4 years who are injured in traffic incidents in the Arab community is 35\% higher than in the Jewish population. Representatives of the ministry of transport said that they planned to invest 22 million shekels (€3.9 million, US\$5.3 million) in an information campaign on road safety for Arab residents.

In 2006, according to the ministry's report, 448 people were killed in traffic incidents- a $6 \%$ drop compared with 2005. The number of road-traffic deaths in 2006 was the lowest in 17 years. Of those killed last year, 139 were pedestrians. Also, there were 780 instances of drivers breaking through traffic barriers at train crossings. Forty percent of the drivers involved in fatal traffic incidents were professionals (truck, bus, and taxi drivers).

The transport minister presented a plan that aims to reduce traffic incidents by $6 \%$ per year. The plan would combine more severe punishment for traffic violators, more enforcement of laws, a change in the points system-whereby violators may accumulate points that lead to a loss of their licence-and traffic education.

In a bid to improve road safety, representatives from the road safety authority suggested that high-school students receive their matriculation certificates only after passing a driver's education course.

From haaretz.com (http://www.haaretz.com/hasen/spages/897551.html). Contributed by Mike Hayes. 